\title{
Investigation of a Self-Aligned Cobalt Silicide Process for Ohmic Contacts to Silicon Carbide
}

\author{
MATTIAS EKSTRÖM (i), ${ }^{1,2}$ ANDREA FERRARIO (10, ${ }^{1}$ \\ and CARL-MIKAEL ZETTERLING (1) ${ }^{1}$
}

1.-Department of Electronics, School of Electrical Engineering and Computer Science, KTH Royal Institute of Technology, 16440 Kista, Sweden. 2.-e-mail: mekstr@kth.se

\begin{abstract}
Previous studies showed that cobalt silicide can form ohmic contacts to $p$-type $6 \mathrm{H}-\mathrm{SiC}$ by directly reacting cobalt with $6 \mathrm{H}-\mathrm{SiC}$. Similar results can be achieved on $4 \mathrm{H}-\mathrm{SiC}$, given the similarities between the different silicon carbide polytypes. However, previous studies using multilayer deposition of silicon/cobalt on $4 \mathrm{H}$-SiC gave ohmic contacts to $n$-type. In this study, we investigated the cobalt silicide/ $4 \mathrm{H}-\mathrm{SiC}$ system to answer two research questions. Can cobalt contacts be self-aligned to contact holes to $4 \mathrm{H}-\mathrm{SiC}$ ? Are the self-aligned contacts ohmic to $n$-type, $p$-type, both or neither? Using x-ray diffraction, it was found that a mixture of silicides $\left(\mathrm{Co}_{2} \mathrm{Si}\right.$ and $\left.\mathrm{CoSi}\right)$ was reliably formed at $800^{\circ} \mathrm{C}$ using rapid thermal processing. The cobalt silicide mixture becomes ohmic to epitaxially grown $n$-type $\left(1 \times 10^{19} \mathrm{~cm}^{-3}\right)$ if annealed at $1000^{\circ} \mathrm{C}$, while it shows rectifying properties to epitaxially grown $p$-type $\left(1 \times 10^{19} \mathrm{~cm}^{-3}\right)$ for all tested anneal temperatures in the range $800-1000^{\circ} \mathrm{C}$. The specific contact resistivity $\left(\rho_{C}\right)$ to $n$-type was $4.3 \times 10^{-4} \Omega \mathrm{cm}^{2}$. This work opens the possibility to investigate other self-aligned contacts to silicon carbide.
\end{abstract}

Key words: Cobalt (Co), rapid thermal processing (RTP), self-aligned silicide, silicon carbide ( $4 \mathrm{H}-\mathrm{SiC})$, transfer length method (TLM)

\section{INTRODUCTION}

The finding that nickel silicide $\left(\mathrm{Ni}_{2} \mathrm{Si}\right)$ can be selfaligned to contact holes to silicon carbide $(4 \mathrm{H}-\mathrm{SiC})^{1,2}$ has opened up new research opportunities. An example of such a study was the finding that the self-aligned $\mathrm{Ni}_{2} \mathrm{Si}$ can be turned from rectifying to ohmic to $p$-type $4 \mathrm{H}-\mathrm{SiC}$ by alloying it with aluminum at relatively low temperatures. ${ }^{3}$ A comparison between self-aligned nickel silicide and lift-off process for power devices was recently presented by Sledziewski at the conference of silicon carbide and related materials (ECSCRM 2018). Nickel-based contact processes give good ohmic contacts to $n$ type $4 \mathrm{H}-\mathrm{SiC},{ }^{2,4,5}$ but often gives rectifying contacts to $p$-type, with some notable exceptions. ${ }^{6-8}$ As such,

(Received October 29, 2018; accepted January 29, 2019; published online February 12, 2019) there is currently missing a single-metal process for self-aligned ohmic contacts to $p$-type. It is known from the mature silicon technology that, in addition to nickel silicide, ${ }^{9-11}$ titanium-, ${ }^{10-13}$ cobalt- ${ }^{10,11,13}$ and platinum-silicide ${ }^{14}$ can be self-aligned. Given the similarities between silicon and $4 \mathrm{H}-\mathrm{SiC}$, some or all of the silicides that can be self-aligned to silicon can be self-aligned to SiC. Thus, it is of interest to investigate the other silicide-forming systems.

Lundberg and Östling ${ }^{15}$ showed that cobalt silicides $\left(\mathrm{CoSi}_{x}\right)$ form ohmic contacts to $p$-type $6 \mathrm{H}$-SiC. The SiC polytypes have similarities and differences. The bandgap energy is similar between the two polytypes $(3.02 \mathrm{eV}$ and $3.26 \mathrm{eV}$ at $300 \mathrm{~K}$ for $6 \mathrm{H}$ and $4 \mathrm{H}$, respectively. ${ }^{16}$ ) The energy difference between vacuum energy $\left(E_{0}\right)$ and valence band edge $\left(E_{V}\right)$ is approximately the same between different polytypes $\left(E_{0}-E_{V} \sim 7.1 \mathrm{eV}\right) .{ }^{17-19}$ If the $\mathrm{CoSi}_{x} / 6 \mathrm{H}-\mathrm{SiC}$ contact that Lundberg and Östling found was a Schottky-Mott-like ohmic contact, it would be 
reasonable to assume that it would also be ohmic to $4 \mathrm{H}$, albeit with a slightly higher Schottky barrier. As such, self-aligned $\mathrm{CoSi}_{x}$ was considered as a candidate for low resistance ohmic contacts to $p$ type $4 \mathrm{H}-\mathrm{SiC}$. However, it is known that contacts to $4 \mathrm{H}-\mathrm{SiC}$ are not perfect Schottky-Mott contacts. $4 \mathrm{H}-$ $\mathrm{SiC}$ contacts have at least partial Fermi-level pinning, ${ }^{20}$ and as such it can be inferred that similar valence band energy does not guarantee similar hole Schottky barrier height. The close chemical similarity between cobalt (atomic number 27) and nickel (atomic number 28) could imply similar characteristics. As such, the $\mathrm{CoSi}_{x} / 4 \mathrm{H}-\mathrm{SiC}$ system could instead give low resistance ohmic contacts to $n$-type $4 \mathrm{H}$-SiC, just like the $\mathrm{Ni}_{2} \mathrm{Si} / 4 \mathrm{H}-$ $\mathrm{SiC}$ system. $\mathrm{CoSi}_{2} / 4 \mathrm{H}-\mathrm{SiC}$, formed by multilayer deposition of silicon and cobalt, has been previously studied and been shown to provide low resistance ohmic contact to $n$-type $4 \mathrm{H}-\mathrm{SiC},{ }^{21-23}$ and the result to $p$-type $4 \mathrm{H}-\mathrm{SiC}$ is unclear. ${ }^{24}$

We investigated the $\mathrm{CoSi}_{x} / 4 \mathrm{H}-\mathrm{SiC}$ system to answer the following two research questions ${ }^{25}$ :

1. Can $\mathrm{CoSi}_{x}$ be self-aligned to $4 \mathrm{H}-\mathrm{SiC}$ ?

2. Does self-aligned $\mathrm{CoSi}_{x}$ form ohmic contacts to $n$-type, $p$-type, both or neither?

In this work, we present the results and conclusions of our investigations. The difference from previous contact studies to $4 \mathrm{H}-\mathrm{SiC}$ is that only cobalt is deposited instead of the silicon/cobalt multilayer stacks. ${ }^{21-23}$ Moreover, interface reactions between cobalt and $4 \mathrm{H}-\mathrm{SiC}$ are studied using rapid thermal processing (RTP) to anneal cobalt $/ 4 \mathrm{H}-\mathrm{SiC}$ instead of furnace annealing cobalt/6H-SiC. ${ }^{26,27}$

The annealing temperature range was limited in this study up to $1000^{\circ} \mathrm{C}$. It was considered that any contact process requiring higher annealing temperatures than $1000^{\circ} \mathrm{C}$ would not be competitive with already established contact processes. ${ }^{2,3,21-23,28-30}$ Higher anneal temperatures could potentially degrade other device related properties, like the silicon dioxide $\left(\mathrm{SiO}_{2}\right) / 4 \mathrm{H}-\mathrm{SiC}$ interface of metal oxide semiconductor field-effect transistors (MOSFETs).

\section{EXPERIMENTAL DETAILS}

Three different sets of $4 \mathrm{H}-\mathrm{SiC}$ samples $(10 \mathrm{~mm} \times 10 \mathrm{~mm}$ pieces $)$ were prepared. The first set was used for x-ray diffraction (XRD) characterization. These pieces came from a $100 \mathrm{~mm} 4^{\circ}$ off-axis cut $n$-type substrate wafer (SiCrystal, $0.0175 \Omega \mathrm{cm}$, corresponding to $\sim 3 \times 10^{18} \mathrm{~cm}^{-3}$ nitrogen doping) with (0001) orientation. Although there may be subtle differences in silicide formation between substrate pieces and epitaxy pieces (through differences in doping and mechanical properties), we assume that the substrate pieces are a good model for silicide formation on epitaxy.
The second set was used to determine the specific contact resistivity to both $n$-type and $p$-type $4 \mathrm{H}$-SiC. The epitaxy was grown by Norstel, and was, from top to bottom: $1 \mu \mathrm{m} n$-type of $10^{19} \mathrm{~cm}^{-3}$ doping concentration and $1 \mu \mathrm{m} p$-type of $10^{18} \mathrm{~cm}^{-3}$ doping concentration. The epitaxy was grown on a $100 \mathrm{~mm}$ $4^{\circ}$ off-axis cut $n$-type substrate wafer. The $p$-type layer provides a $p n$-junction isolation for the top $n$ type layer, and the $p$-type layer is isolated from the $n$-type substrate by the formed $p n$-junction. These doping levels correspond to those used in our inhouse bipolar junction transistor (BJT) technology, and as such it would be an interesting finding if the cobalt contacts would provide low resistance ohmic contacts to both $n$-type and $p$-type at the same time.

The third and final set had highly doped $p$-type epitaxy. The epitaxy was grown by Norstel and was, from top to bottom: $200 \mathrm{~nm} p$-type of $10^{19} \mathrm{~cm}^{-3}$ doping concentration, $800 \mathrm{~nm} n$-type $10^{16} \mathrm{~cm}^{-3}$ doping concentration, and $1 \mu \mathrm{m} p$-type of $5 \times$ $10^{18} \mathrm{~cm}^{-3}$ doping concentration. The epitaxy was grown on a $100 \mathrm{~mm} 4^{\circ}$ off-axis cut $n$-type substrate wafer. The different $p n$-junctions provide isolation between the different layers. This third set has a higher $p$-type doping than the second set, which should enhance field emission (FE) by having a narrower depletion region. If the $\mathrm{CoSi}_{x}$ would form low resistance ohmic contacts to $p$-type, it was expected that this third set would have lower contact resistance to $p$-type than the second set.

The samples with epitaxy (sets 2 and 3) were prepared to have transfer length method (TLM) structures by forming TLM mesas. These mesas limit the current flow to laminar flow between contacts. By limiting the current flow, the accuracy of the extraction of the specific contact resistivity is improved. ${ }^{31}$ The mesas were patterned by standard optical lithography and were dry etched by magnetically enhanced reactive ion etching (MERIE). The second set was etched twice in order to provide mesa isolation for both $n$-type and $p$-type, whereas the third set was etched once to provide isolation for the top $p$-type layer. Since dry etching induces surface damage, the wafers underwent sacrificial oxidation, where the surface is oxidized and removed by stripping the grown oxide with hydrofluoric acid. At this point, all three wafers could be diced into pieces for further processing.

All three sets of samples were cleaned in Piranha solution $\left(\mathrm{H}_{2} \mathrm{SO}_{4}\right.$ mixed with $\left.\mathrm{H}_{2} \mathrm{O}_{2}\right)$ for 5 min to remove any organic material, followed by diluted $\mathrm{HF}(\mathrm{dHF})$ for 5 min to remove any chemical $\mathrm{SiO}_{2}$.

To enable the self-aligned process, a $50 \mathrm{~nm} \mathrm{SiO}{ }_{2}$ film was deposited by atomic layer deposition (ALD) at $350^{\circ} \mathrm{C}$ with ozone $\left(\mathrm{O}_{3}\right)$ and a commercial precursor (AP-LTO-330) on the epi-layer samples. This $\mathrm{ALD}-\mathrm{SiO}_{2}$ film has a very low density of pinholes and provides excellent isolation to prevent unwanted $\mathrm{Co} / 4 \mathrm{H}-\mathrm{SiC}$ reactions. The $\mathrm{SiO}_{2}$ film also provides some surface passivation. In preparation 
for a future dHF-dip, the $\mathrm{SiO}_{2}$ was hardened by annealing it in a RTP tool (a Mattson 100 RTP system) for $30 \mathrm{~s}$ at $1000^{\circ} \mathrm{C}$ in $\mathrm{N}_{2}$ ambient. Contact holes were patterned by standard optical lithography and opened with a conventional polymer-forming fluorine-based $\left(\mathrm{Ar} / \mathrm{CF}_{4} / \mathrm{CHF}_{3}\right)$ MERIE process that etches $\mathrm{SiO}_{2}$ selectively to $4 \mathrm{H}-\mathrm{SiC}$. The resist was stripped by chemical remover and post-cleaned with solvents. To ensure complete removal of organics, the samples were further cleaned by $\mathrm{O}_{2}$ plasma and 5 min Piranha.

Before cobalt deposition, all three sets were cleaned by dipping the samples in $\operatorname{dHF}\left(10: 1 \mathrm{H}_{2} \mathrm{O}\right.$ : $5 \% \mathrm{HF} v / v$ ) for $10 \mathrm{~s}$ followed by thorough rinsing and drying. Cobalt was deposited in a Lesker CMS-18 magnetron sputter operated in direct-current magnetron sputtering (DCMS) mode with an average discharge power of $130 \mathrm{~W}$. The sputtering gas was argon at a pressure of $1.1 \mathrm{~Pa}$ and a mass flow of 80 sccm. At these conditions, the deposition rate was $2.33 \mathrm{~nm} / \mathrm{min}$. No intentional heating was used, nor was backsputtering performed to pre-clean the samples. $10 \mathrm{~nm}$ of cobalt was deposited on the episamples and $40 \mathrm{~nm}$ of cobalt was deposited on the XRD samples. It was considered that the direct cobalt $/ 4 \mathrm{H}-\mathrm{SiC}$ reaction would release large amount of carbon that could be detrimental for the contact. The thin film thickness of $10 \mathrm{~nm}$ is primarily motivated by the need to reduce the amount of released carbon. Cobalt, like nickel and platinum, does not form carbides when directly reacting with $4 \mathrm{H}-\mathrm{SiC}$. The released carbon forms precipitates inside of the silicide film, or graphite if the annealing temperature is sufficiently high. ${ }^{27}$ One of the motivations for the multilayer silicon/cobalt depositions was to reduce the amount of released carbon. ${ }^{15,21-23}$ The $40 \mathrm{~nm}$ cobalt was motivated by the need to have strong XRD signals. A few substrate pieces (set 1) had only $10 \mathrm{~nm}$ cobalt, which was used in XRD and scanning electron microscopy (SEM).

The XRD samples were annealed in the temperature range $600-850^{\circ} \mathrm{C}$ using the RTP system for $30-240 \mathrm{~s}$ in $\mathrm{N}_{2}$ ambient. The samples were annealed inside of a graphite box that was heated by lamps. The high thermal mass of the graphite box prevents investigating anneal times shorter than $30 \mathrm{~s}$, and $240 \mathrm{~s}$ was the longest time allowed without damaging the RTP system. The temperature was controlled in a feedback loop by an optical pyrometer that measures the temperature of the graphite box. The pyrometer was calibrated by thermocouple measurement of a silicon wafer inside of the graphite box. The oxygen content inside of the chamber was monitored by an $\mathrm{O}_{2}$-meter. The chamber was purged with nitrogen until the oxygen content was below one part per million $(v / v)$ before ramping up to process temperature. The error in steady-state temperature is a few degrees celsius $\left(<10^{\circ} \mathrm{C}\right)$ for this setup. It was found that $\mathrm{CoSi}_{x^{-}}$ phase could be formed reliably at $800^{\circ} \mathrm{C}$ from the XRD results (see "Structural Characterization"

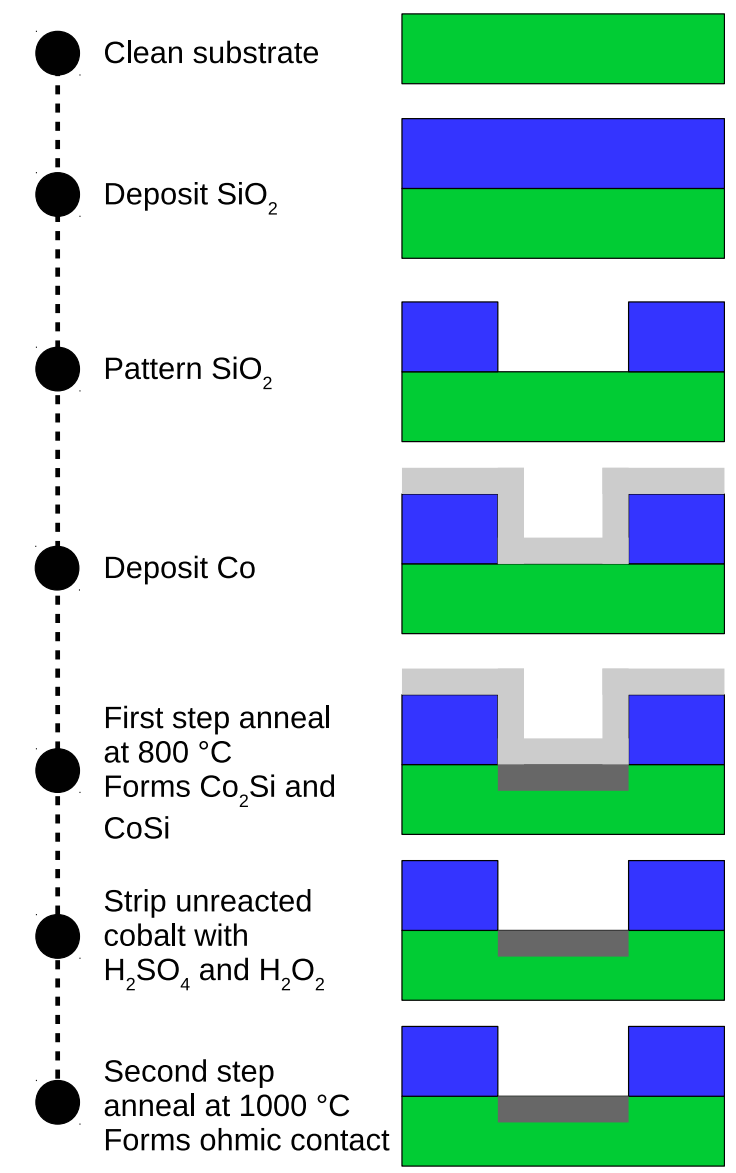

Fig. 1. Simplified process flow for ohmic contact formation to $n$-type SiC using cobalt silicide.

Section), which was selected as the first-step anneal (FSA) of the self-aligned process.

The unreacted cobalt was stripped by Piranha solution after the FSA. The samples were annealed a second time at temperatures varying from $850^{\circ} \mathrm{C}$ to $1000^{\circ} \mathrm{C}$ in steps of $50^{\circ} \mathrm{C}$, with the time $(60 \mathrm{~s})$ and ambient $\left(\mathrm{N}_{2}\right)$ remaining the same amongst the samples. One sample from each of the two epi-layer sets was not subjected to the second-step anneal (SSA) to check if the FSA was sufficient to form ohmic contacts.

The samples were further processed by depositing metallization (TiW and aluminum) to allow for measurement pads. The metallization was patterned by standard optical lithography and etched by a combination of reactive ion etching (RIE) and wet etching.

A simplified self-aligned process flow is shown in Fig. 1. The TLM structures (without TiW/Al metallization) are illustrated in Fig. 2.

The XRD characterization was performed by $\theta-2 \theta$ scan using a PANalytical Empyrean with $\mathrm{Cu} \mathrm{K}_{\alpha, 1}$ radiation. The incident $\mathrm{x}$-ray beam optics included a nickel filter (removes $\mathrm{Cu} \mathrm{K}_{\beta}$ radiation), a hybrid $2 \times$ $\mathrm{Ge}(220)$ monochromator [an x-ray mirror and two 
Set 2: $n$-type and p-type

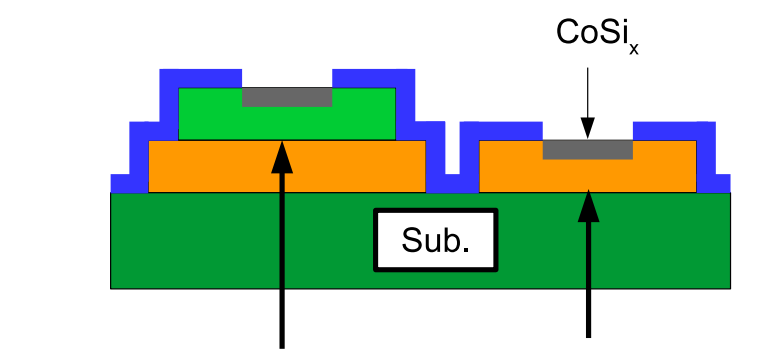

$n$-type, $1 \mu \mathrm{m}, 10^{19} \mathrm{~cm}^{-3} \quad p$-type, $1 \mu \mathrm{m}, 10^{18} \mathrm{~cm}^{-3}$

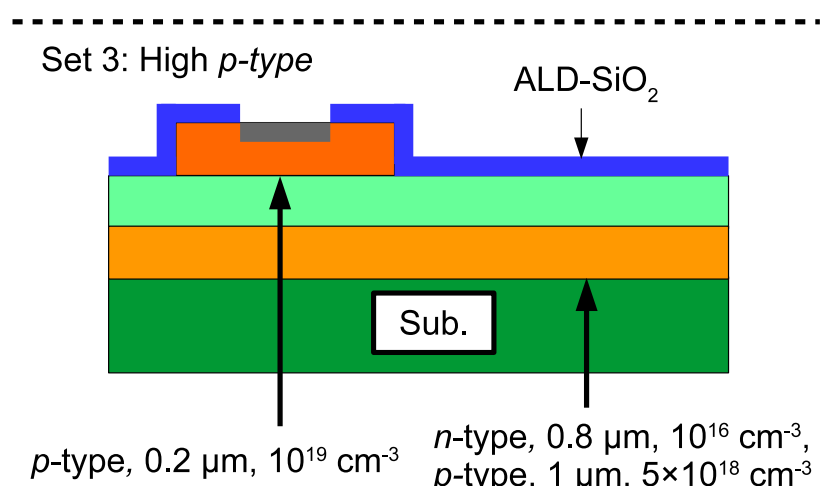

Fig. 2. Simplified cross-section view of the TLM structures used in this study (not drawn to scale). Set 2 samples had both $n$-type and $p$ type TLM structures, whereas set 3 had high $p$-type doping. This drawing is without top-level metallization.

$\mathrm{Ge}(220)$ crystals that suppress the $\mathrm{CuK}_{\alpha, 2}$ radiation], a $0.125^{\circ}$ divergence slit, a $0.5^{\circ}$ anti-scatter slit, a Soller slits assembly and a beam-mask. The diffracted beam path consisted of fixed anti-scatter slits and another Soller slits assembly. The samples were mounted on a reflection-transmission spinner. The surface morphology was investigated by SEM using a Zeiss Ultra 55 with with an in-lens detector that images the topography and an integrated energy-dispersive x-ray spectroscopy (EDS) system. SEM images were captured with an electron beam energy of $2 \mathrm{keV}$, whereas the x-ray signal for EDS analysis was excited with an electron beam energy of $10 \mathrm{keV}$. The electrical characterization was performed with a Cascade 11000 probestation connected to a Keithley 4200-SCS. The samples were inside of a microchamber that shields the samples from ambient light and electromagnetic interference. Four-probe measurement (Kelvin measurement) was used to eliminate the resistance of the cables.

\section{RESULTS AND DISCUSSION}

\section{Structural Characterization}

The measured XRD spectra of substrate samples with $40 \mathrm{~nm}$ cobalt are shown in Fig. 3. The asdeposited cobalt films do not exhibit any XRD peak that corresponds to crystalline cobalt. A possible explanation is that the film is nanocrystalline and the crystallinity cannot detected in $\theta-2 \theta$ scans,

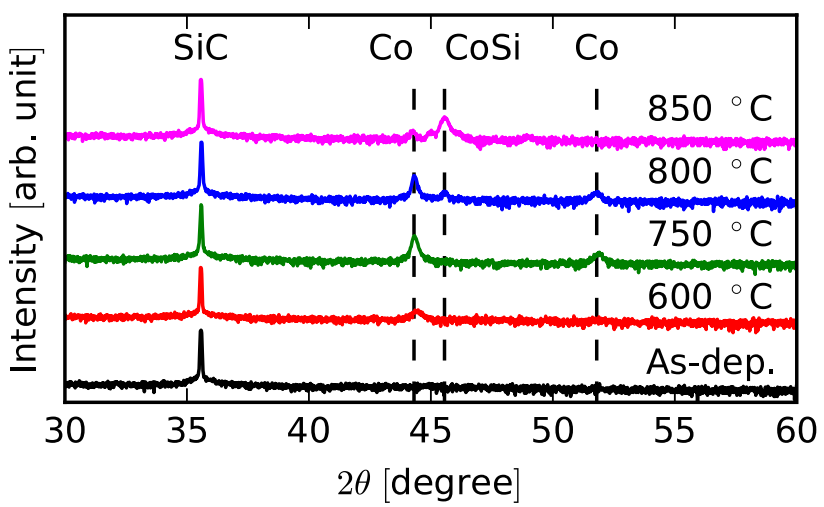

Fig. 3. XRD spectra of $\mathrm{CoSi}_{x} / \mathrm{SiC}$. The as-deposited film does not show enough large-grain crystallinity to be detected by $\theta-2 \theta$ scans. The cobalt film crystallizes at $600^{\circ} \mathrm{C}$. The cobalt silicides form at $800^{\circ} \mathrm{C}$ and above by RTP, $60 \mathrm{~s}$. The initial cobalt thickness was 40 $\mathrm{nm}$ for all samples.

although it may be detected by grazing-incidence $x$-ray diffraction (GIXRD). ${ }^{32}$ The cobalt signal emerges after annealing the film at $600^{\circ} \mathrm{C}$ at $2 \theta=44.3^{\circ}$, correspondig to cubic (111), and around $2 \theta=52^{\circ}$, corresponding to cubic $(200){ }^{26}$ The film likely forms large polycrystalline grains at this anneal temperature that can be detected by the $\theta-$ $2 \theta$ scan. Annealing at $750^{\circ} \mathrm{C}$ increases the cobalt signal. Both $\mathrm{Co}_{2} \mathrm{Si}$ at $2 \theta=44.3^{\circ}$, corresponding to (021), and $\mathrm{CoSi}$ at $2 \theta=45.5^{\circ}$, corresponding to (210), are found at $800^{\circ} \mathrm{C}$. This temperature is somewhat lower than the lowest tested temperature in Ref. $27\left(850^{\circ} \mathrm{C}\right)$, but higher than the formation temperature found by Ref. 26. It should be stressed that polycrystalline $6 \mathrm{H}-\mathrm{SiC}$ and anneals longer than 10 min was used in the work of Ref. 26 to find $\mathrm{Co}_{2} \mathrm{Si}$ at $650^{\circ} \mathrm{C}$. It is surprising to find both $\mathrm{Co}_{2} \mathrm{Si}$ and $\mathrm{CoSi}$ co-existing at this narrow anneal condition. Given the auricupride-rule, the most mobile species determines the first phase. As such, it is commonly observed that the first phase is the metal-rich silicide $\left(\mathrm{X}_{2} \mathrm{Si}, \mathrm{X}=\mathrm{Co}, \mathrm{Ni}, \mathrm{Ti}, \mathrm{Pt}\right) .{ }^{11,26,27}$ Given the finding that $\mathrm{Co}_{2} \mathrm{Si}$ may form at $650^{\circ} \mathrm{C}$ after long anneals, the process bottleneck appears to be the nucleation of $\mathrm{Co}_{2} \mathrm{Si}$. The thermally activated probability per unit time of nucleating the silicide increases with increasing temperature, and as such $\mathrm{Co}_{2} \mathrm{Si}$ may form within $60 \mathrm{~s}$ at $800^{\circ} \mathrm{C}$ with very high probability but with very low probability at $750^{\circ} \mathrm{C}$. CoSi may also form at this temperature, but requires that $\mathrm{Co}_{2} \mathrm{Si}$ forms first. However, to verify these assumptions would require detailed investigation at the kinetics of formation of the cobalt/4H-SiC system which was outside the scope of this study. Higher annealing temperatures transform the $\mathrm{Co} / \mathrm{Co}_{2} \mathrm{Si}$ to $\mathrm{CoSi}$, as evident by the decreased signal at $2 \theta=44.3^{\circ}$ [cubic cobalt $(200)$ and $\left.\mathrm{Co}_{2} \mathrm{Si}(021)\right]$ and increased signal at $2 \theta=45.5^{\circ}[\mathrm{CoSi}$ (210)].

To verify that the $\mathrm{CoSi}_{x}$ had formed at $800^{\circ} \mathrm{C}$, the sample was submerged in Piranha solution to etch cobalt selectively to the silicides. The sample was remeasured and it was found that the signal at $2 \theta=$ 
$44.3^{\circ}$ decreased [reduced cubic cobalt (200) signal] but did not disappear $\left[\mathrm{Co}_{2} \mathrm{Si}(021)\right.$ signal remained]. It appears that $\mathrm{Co}, \mathrm{Co}_{2} \mathrm{Si}$ and $\mathrm{CoSi}$ coexist at $800^{\circ} \mathrm{C}$. This has been observed in previous studies on $6 \mathrm{H}$ $\mathrm{SiC}^{26}$ and in silicon technology. ${ }^{13}$

A difference from the nickel/4H-SiC system is that both $\mathrm{Co}_{2} \mathrm{Si}$ and $\mathrm{CoSi}$ are formed, whereas $\mathrm{Ni}_{2} \mathrm{Si}$ is thermally stable for typical process temperatures. The co-existence of multiple phases can be both beneficial and detrimental. The use of phase-segregation in $\mathrm{Pt}: \mathrm{Ti} / 4 \mathrm{H}-\mathrm{SiC}$ system allows for ohmic contacts to both $p$-type and $n$-type by having locally varying Schottky barrier height, ${ }^{28}$ and as such having multiple $\mathrm{CoSi}_{x}$ phases could give simultaneous contacts. However, if only one phase gives ohmic contacts to one of the types, then the contact would exhibit high resistance. As such, it is important to have control of which phase is present. Phase control appears difficult at low temperatures $\left(\sim 800^{\circ} \mathrm{C}\right)$, due to $\mathrm{Co}, \mathrm{Co}_{2} \mathrm{Si}$ and $\mathrm{CoSi}$ coexisting. Phase control is possible by having high temperature anneal, since the final silicide phase is CoSi in the $\mathrm{Co} / 4 \mathrm{H}-\mathrm{SiC}$ system.

The time required to form the silicide was investigated by varying the anneal time, $30 \mathrm{~s}, 60 \mathrm{~s}$ and $240 \mathrm{~s}$. The $\mathrm{CoSi}_{x}$-signals are weak but present at 30 $\mathrm{s}$, and there was no significant difference between $60 \mathrm{~s}$ and $240 \mathrm{~s}$. As such, it was determined that annealing at $800^{\circ} \mathrm{C}$ for $60 \mathrm{~s}$ was the most suitable FSA condition. This temperature is $200^{\circ} \mathrm{C}$ higher than that of the FSA of the self-aligned nickel silicide contacts to $4 \mathrm{H}-\mathrm{SiC}$ for the same annealing conditions (RTP process) and time. ${ }^{2}$ It is possible that the nucleation can be enhanced, and thus lower the temperature, by having a cleaner interface during the deposition. In situ clean by backsputtering and thermal desorption of moisture by in-situ heat treatment prior to deposition are two possible improvements. Reducing the FSA temperature would greatly improve the process, as it would inhibit the defect formation mechanisms that are typical of self-aligned silicide processes. While direct reaction of cobalt with $\mathrm{SiO}_{2}$ at $800^{\circ} \mathrm{C}$ is thermodynamically unfavorable, ${ }^{33}$ cobalt can react with $\mathrm{SiO}_{2}$ at $800^{\circ} \mathrm{C}$ in the presence of oxygen contamination. ${ }^{34}$ To avoid this possibility, the FSA temperature should be kept under $700^{\circ} \mathrm{C}^{10}$ In the absence of reaction, the cobalt could conceivably diffuse through the $\mathrm{SiO}_{2}$ through defects or pinholes (depending on the quality of $\mathrm{SiO}_{2}$ ) and react with the underlying $4 \mathrm{H}-\mathrm{SiC}$. Of more concern is the commonly observed silicon-diffusion causing bridgingfault, wherein silicon atoms, which are the dominant diffusers in forming $\mathrm{CoSi}$, diffuse from the silicon source (in this case $4 \mathrm{H}-\mathrm{SiC}$ ) through the CoSi and reacts with the cobalt lying on the $\mathrm{SiO}_{2}$ between contacts. There, it can form a silicide that bridges between contacts and cause short-circuit. ${ }^{10,11,13}$ Reducing the temperature would reduce the thermally activated diffusion of both cobalt through $\mathrm{SiO}_{2}$ and silicon through $\mathrm{CoSi} .{ }^{13}$ Unless future studies find a way to reduce this FSA temperature, the cobalt self-aligned process will result in poor yield due to the generation of a high number of defects.

The surface morphology was studied by SEM and chemically by EDS. The samples that were imaged were substrate pieces with varying initial cobalt thickness (both $10 \mathrm{~nm}$ and $40 \mathrm{~nm}$ ). The $10 \mathrm{~nm}$ cobalt sample is patchy and non-uniform after the FSA but before stripping the cobalt (Fig. 4). EDS detects that the surface is covered with cobalt, as expected. Samples with stripped remaining cobalt are different for different initial cobalt thicknesses. The thin $10 \mathrm{~nm}$ cobalt sample have hexagonal crystallites on the surface, as seen in Fig. 5a. The hexagonal crystallites have a much higher $\mathrm{CoL}_{\alpha}$ signal than the surrounding (darker) area, and as such these crystallites are likely the remaining $\mathrm{CoSi}_{x}$. However, the thick $40 \mathrm{~nm}$ cobalt sample give a very different surface. The cobalt has reacted with $4 \mathrm{H}$ $\mathrm{SiC}$, as seen by the blistered surface in Fig. 5b. The blistered surface is not $\mathrm{CoSi}_{x}$, according to EDS. The $\mathrm{CoSi}_{x}$ itself is a dendric-like structure. As such, the $\mathrm{CoSi}_{x}$ appears to break when the initial thickness is $40 \mathrm{~nm}$. The $\mathrm{CoSi}_{x}$ does not form a continuous film in both cases. Similar results can be found in silicon technology. Thinner films are dominated by the interface energy and allows better silicidation growth, whereas thicker films can break because they are unable to handle the strain at the silicide/ silicon. ${ }^{35}$ However, thin films agglomerate (form islands) easier than thick films. ${ }^{13}$ As such, the choice of initial cobalt thickness turned out to be non-trivial. Future studies could investigate the thickness dependence.

\section{Electrical Characterization}

For the purpose of determining if the contacts were ohmic or not, a pair of adjacent TLM contacts were measured by sweeping the current, from $-10 \mu \mathrm{A}$ to $10 \mu \mathrm{A}$ in steps of $1 \mu \mathrm{A}$, and measuring the voltage drop. An ohmic contact produces a

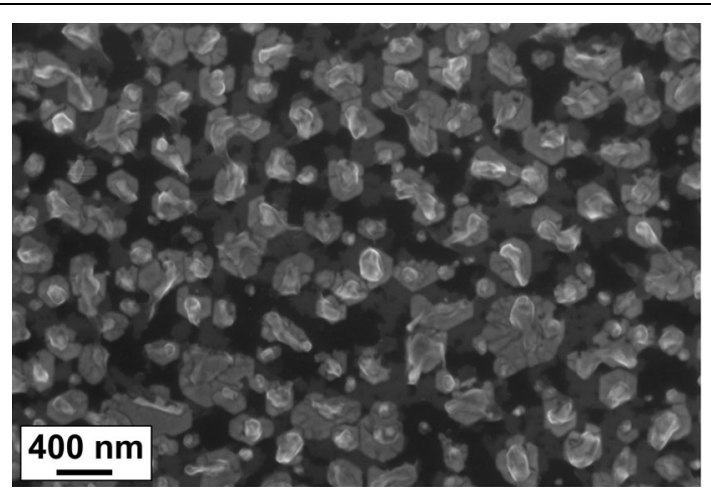

Fig. 4. SEM image of cobalt silicide mixture, formed at $800^{\circ} \mathrm{C}, \mathrm{RTP}$ and $60 \mathrm{~s}$ from $10 \mathrm{~nm}$ cobalt $/ 4 \mathrm{H}-\mathrm{SiC}$. The sample has not been stripped of unreacted cobalt. The surface is patchy and non-uniform. 

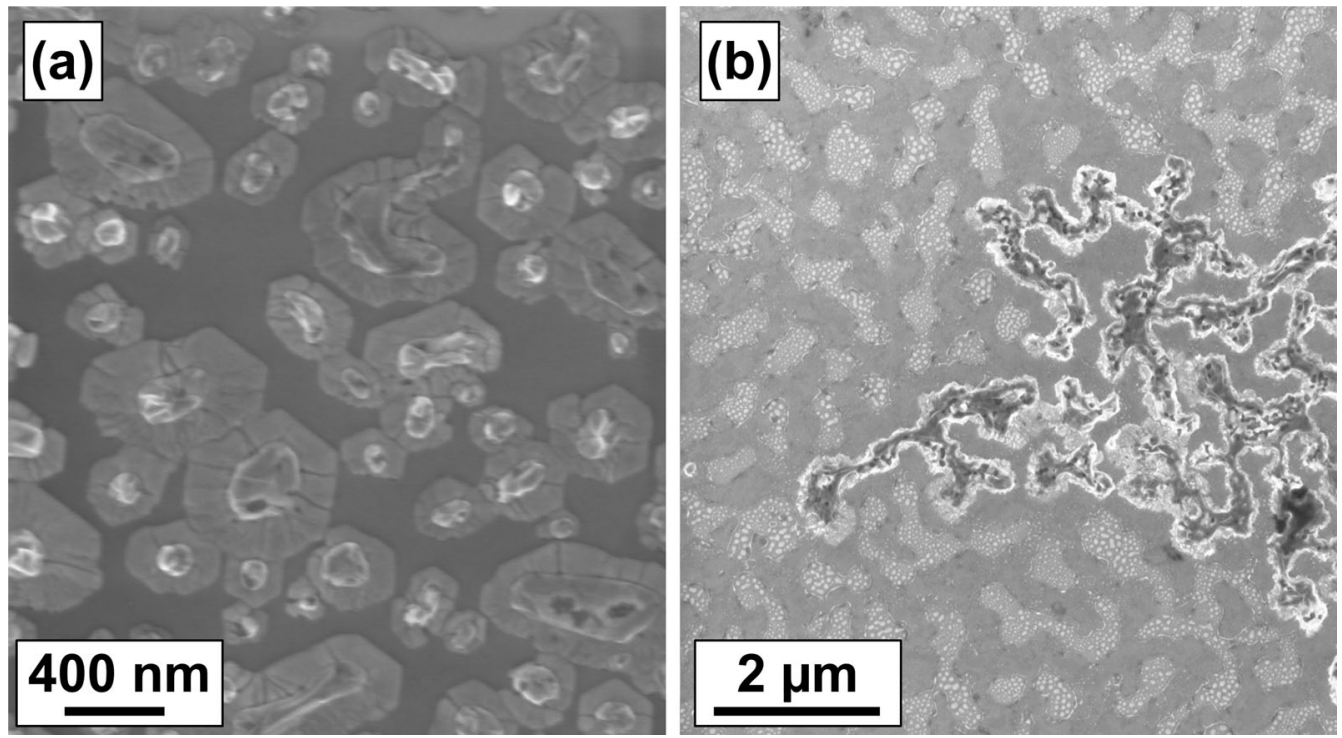

Fig. 5. SEM image of cobalt silicide, formed at $800^{\circ} \mathrm{C}$, RTP and $60 \mathrm{~s}$ from cobalt/4H-SiC. The unreacted cobalt has been stripped. (a) The sample had $10 \mathrm{~nm}$ initial cobalt thickness. The $\mathrm{CoSi}_{x}$ forms hexagonal islands by agglomeration. Since CoSi $\mathrm{i}_{x}$ is cubic/orthorhombic, it appears to grow textured partially in the $\{111\}$ direction. (b) The sample had $40 \mathrm{~nm}$ initial cobalt thickness. The CoSi $\mathrm{C}_{x}$ film has broken and forms dendric-like structures, as seen in the center right-hand side part of the figure. The surrounding $4 \mathrm{H}-\mathrm{SiC}$ surface appears blistered, which indicates the the cobalt had a reaction with the $4 \mathrm{H}-\mathrm{SiC}$ before breaking. Note that the magnification is higher in (a) than (b).
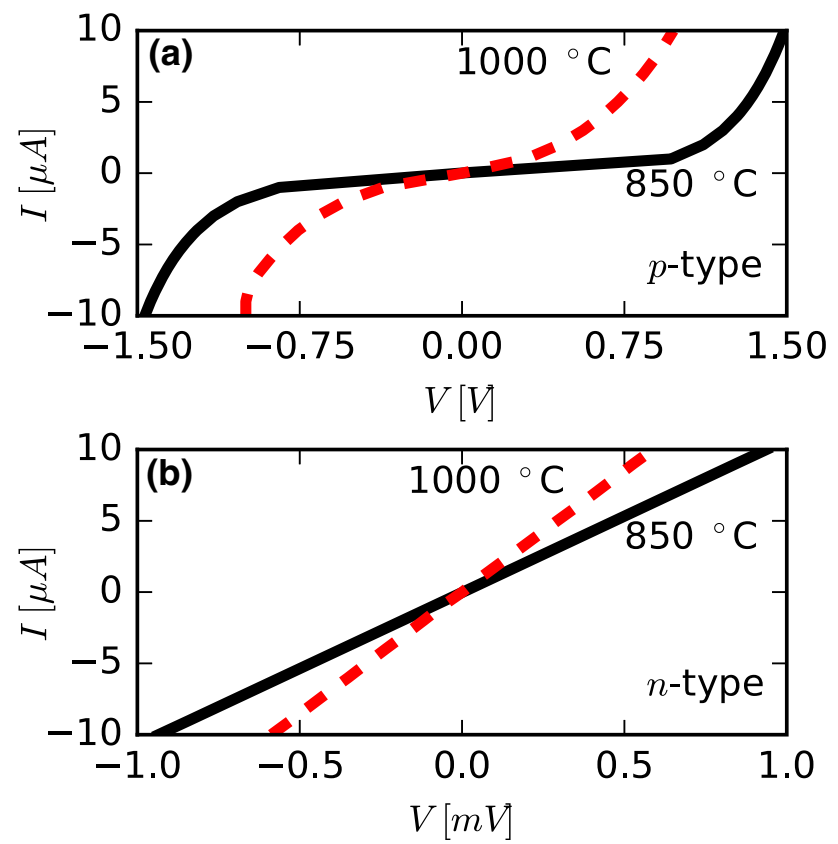

Fig. 6. $I-V$ curves from measured contact pairs. (a) shows contacts to $p$-type $4 \mathrm{H}-\mathrm{SiC}$ and (b) shows contacts to $n$-type $4 \mathrm{H}$ $\mathrm{SiC}$, both with a doping concentration of $10^{19} \mathrm{~cm}^{-3}$. The contacts to $p$-type $4 \mathrm{H}-\mathrm{SiC}$ show ' $\mathrm{S}$ ' curve and are non-ohmic. The contacts to $n$ type $4 \mathrm{H}-\mathrm{SiC}$ are ohmic after annealing at $850^{\circ} \mathrm{C}$ and the resistance decreases with higher anneal temperature. The solid lines are for contacts annealed at $850^{\circ} \mathrm{C}$ and the dashed lines for contacts annealed at $1000^{\circ} \mathrm{C}$. Note that the voltage scale differs for $n$-type and $p$-type, while the same current scale is used.

straight line in an $I-V$ plot, whereas non-ohmic contacts produce an 'S'-curve. A selected few $I-V$ curves are shown in Fig. 6.
All measured contact pairs on $p$-type, regardless of the doping level used, showed "S"-curve (as seen in Fig. 6a), indicating that the contacts were very poor. The partially rectifying behaviour also demonstrates that there are no metallic short-circuits between the contacts, which would be caused by cobalt $/ 4 \mathrm{H}-\mathrm{SiC}$ reaction under the $\mathrm{SiO}_{2}$ or by bridging between the contacts. $\mathrm{CoSi}_{x}$ formed only in the open contact areas, otherwise there would have been metallic short-circuits. The resistance of the $p$ type contacts decreased by higher SSA temperature, but it was still partially rectifying even at $1000^{\circ} \mathrm{C}$. Even if the contacts become ohmic at a higher annealing temperature, the process is unlikely to be competitive with already established contact processes. ${ }^{3,28-30}$ As such, it was found that the selfaligned $\mathrm{CoSi}_{x}$ is a poor candidate for low resistance ohmic contacts to $p$-type $4 \mathrm{H}-\mathrm{SiC}$. It is interesting to compare the result to that achieved by Lundberg and Östling. ${ }^{15}$ They achieved ohmic contacts (about $10^{-3} \Omega \mathrm{cm}^{2}$ ) by annealing $120 \mathrm{~nm} \quad \mathrm{Co} / 6 \mathrm{H}-\mathrm{SiC}$ $\left(2 \times 10^{19} \mathrm{~cm}^{-3}\right.$, epitaxy $)$ at $900^{\circ} \mathrm{C}$ for $2 \mathrm{~h}$ in a vacuum furnace. Five parameters are different between these experiments: doping concentration, thickness, time, polytype and annealing system. The twice higher doping gives $1.4 \times$ narrower depletion width, which may be sufficient to enable tunneling. However, contacts to $4 \mathrm{H}-\mathrm{SiC}$ are almost always determined by thermionic field emission (TFE) and not $\mathrm{FE}$, and as such this small doping concentration difference may not be enough to change a rectifying contact to an ohmic contact. The thickness may play a role if the amount of released carbon is important-otherwise the interface alone should determine the contact properties. Since the process 


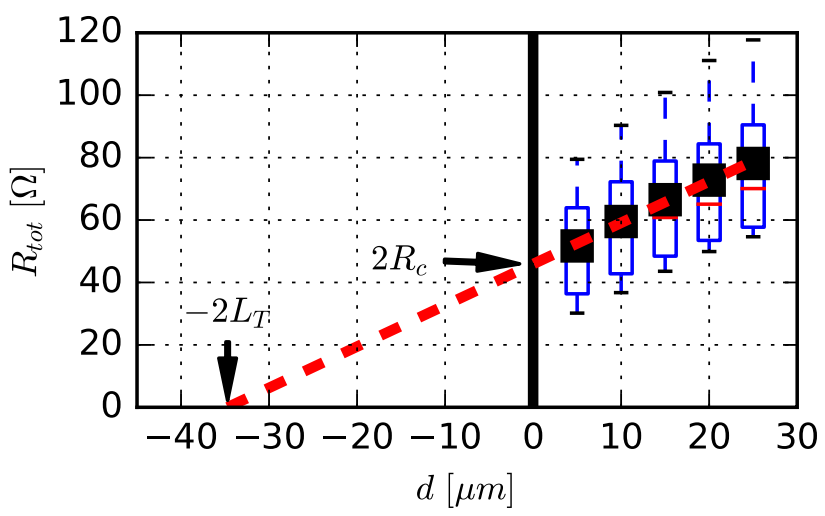

Fig. 7. TLM boxplot of cobalt silicide contacts to $n$-type $4 \mathrm{H}-\mathrm{SiC}$, annealed at $1000^{\circ} \mathrm{C}$. The whiskers show the range of total resistance $\left(R_{t o t}\right)$ values of the four measured TLM structures. The contact resistance $\left(2 R_{c}\right)$ is given by the intercept at zero separation distance (d). The transfer length $\left(2 L_{T}\right)$ is given by the intercept at zero resistance. The separation distance of the contacts were $5 \mu \mathrm{m}$, $10 \mu \mathrm{m}, 15 \mu \mathrm{m}, 20 \mu \mathrm{m}$ and $25 \mu \mathrm{m}$, and the width was $100 \mu \mathrm{m}$.

bottleneck is the silicide nucleation, the time and temperature might not be the most important parameters for a Schottky-Mott contact-a higher temperature together with a shorter time can produce the same silicide as a lower temperature for a longer anneal time. What might be important is to have one $\mathrm{CoSi}_{x}$-phase instead of having a mixture, which would be achieved by a long anneal. The same silicide should, ideally, give the same work function. As argued in the introduction, while there are differences between the polytype, the valence bands are similar, and as such the Schottky barrier should be similar between the different polytypes for the same metal work function. It is possible that the higher resistance observed for our contacts is entirely due to the small difference in Schottky barrier, but it is also possible that these contacts are not Schottky-Mott contacts, but some other intermediate contacts, like metal-induced gap states (MIGS) contact.

Ohmic contact behaviour was found for all contacts to $n$-type $4 \mathrm{H}-\mathrm{SiC}$ annealed at $850^{\circ} \mathrm{C}$ and higher, as seen in Fig. 6b. Higher SSA temperatures give lower contact resistance. However, the contacts produced a very high resistance with high variability up to $1000^{\circ} \mathrm{C}$ anneal temperature. Because of this variability, it was not possible to fit the data to the TLM-model-the variation was larger than the resistance difference due to the $n$-type sheet resistance. Only the sample annealed at $1000^{\circ} \mathrm{C}$ gave low enough contact resistance with low variability to fit the data to the TLM-model, as shown in Fig. 7. The extracted specific contact resistivity of the $1000^{\circ} \mathrm{C}$ sample was, averaged over four structures, $4.3 \times 10^{-4} \Omega \mathrm{cm}^{2}$ (sample standard deviation was $2.7 \times 10^{-4} \Omega \mathrm{cm}^{2}$ ) at room temperature. Compared to the $\mathrm{CoSi}_{2} / 4 \mathrm{H}-\mathrm{SiC}$ contacts, produced by multilayer silicon/cobalt deposition, the result is unfavourable. Cho et al. achieved $\rho_{C}$ of $1.8 \times 10^{-6} \Omega \mathrm{cm}^{2}$ by annealing at $800^{\circ} \mathrm{C}$ for $2 \mathrm{~min} .{ }^{21,22}$ Smedfors et al. achieved $\rho_{C}$ of $3.8 \times 10^{-5} \Omega \mathrm{cm}^{2}$ by annealing at $950^{\circ} \mathrm{C}$ for $1 \mathrm{~min} .{ }^{23} \mathrm{It}$ is stressed that the doping of our samples are nominally identical to those of Smedfors et al. While the multilayer deposition process is more complex, as it requires both lift-off and capability to deposit silicon and cobalt at the same time unlike the self-aligned and direct reaction between $\mathrm{Co} / 4 \mathrm{H}-\mathrm{SiC}$, it achieves better results. A major difference between previous contacts and these contacts is that the multilayer contacts produce silicon-rich $\mathrm{CoSi}_{2}$ as final phase, whereas our approach gives metal-rich phases $\left(\mathrm{Co}_{2} \mathrm{Si}\right.$ and $\left.\mathrm{CoSi}\right)$. It might be inferred that $\mathrm{CoSi}_{2}$ results in better contacts to $n$-type $4 \mathrm{H}$-SiC than the other silicide phases. $\mathrm{CoSi}_{2}$ gives a smaller electron Schottky barrier height to silicon than $\mathrm{CoSi},{ }^{11}$ which might be same case for $4 \mathrm{H}-\mathrm{SiC}$. There could be other reasons why the multilayer approach gives lower contact resistivity. The multilayer approach minimizes the reaction with $4 \mathrm{H}-\mathrm{SiC}$, which minimizes surface roughening and carbon release, which in turn could give lower contact resistivity. Another observation is that the microstructure of our $\mathrm{CoSi}_{x}$ has agglomerated into islands and is not a continuous film, whereas there is a continuous film in both of the work of Cho et al. ${ }^{21}$ and Smedfors et al. ${ }^{23}$ (although in the latter case voids were seen in SEM). The crystallites would form point-contacts and behave differently from the continous film case seen in the previous studies.

Compared to the already established self-aligned nickel silicide process, the result is also unfavourable. Elahipanah et al. ${ }^{2}$ achieved $\rho_{C}$ of $5 \times 10^{-6} \Omega \mathrm{cm}^{2}$ by annealing at $950^{\circ} \mathrm{C}$ for $1 \mathrm{~min}$ as the SSA.

The sheet resistance showed considerable spread in values, ranging from $101 \Omega /$ to $194 \Omega /$. This may influence the contact result if the doping variation is the primary cause of sheet resistance variation. This small dataset does not show correlation (the $p$ value of the null-hypothesis, no correlation, is $60 \%$ ), and as such we cannot show that the doping is causing the specific contact resistivity variation. However, the average sheet resistance $(132 \Omega /)$ is within the expected order of magnitude. ${ }^{23}$

\section{CONCLUSIONS}

This study investigated if cobalt silicide could be self-aligned to contact holes to $4 \mathrm{H}-\mathrm{SiC}$ and give ohmic contacts to $n$-type, $p$-type, both or neither. We successfully found that self-aligned cobalt silicide forms ohmic contacts to $n$-type by first annealing at $800^{\circ} \mathrm{C}$, stripping the remaining cobalt, followed by a second anneal at $1000^{\circ} \mathrm{C}$. While successful, the performance of this contact is inferior to the already established self-aligned nickel silicide contact process. Both the temperature formation and specific contact resistivity is higher for the cobalt silicide than that of the nickel silicide process. The 
presented process could possibly be improved by In situ cleaning during sputtering and by using different film thicknesses, but this remains to be investigated.

With this study, we have shown that not only nickel silicide can be self-aligned to $4 \mathrm{H}-\mathrm{SiC}$, and as such future work could be to investigate if the other two silicide forming systems, $\mathrm{Ti} / 4 \mathrm{H}-\mathrm{SiC}$ and $\mathrm{Pt} / 4 \mathrm{H}-$ $\mathrm{SiC}$, can form self-aligned ohmic contacts. It is possible that the combinations $\mathrm{Ni}: \mathrm{Pt} / 4 \mathrm{H}-\mathrm{SiC}$ and $\mathrm{Pt}: \mathrm{Ti} / 4 \mathrm{H}-\mathrm{SiC}$ could also be self-aligned.

\section{ACKNOWLEDGMENTS}

Thanks goes to Tomas Kubart for assisting in the cobalt deposition. Thanks goes to Gunnar Malm, who provided much appreciated feedback on the manuscript. The authors thank the Knut and Alice Wallenberg Foundation for funding this research as a part of the Working on Venus project.

\section{OPEN ACCESS}

This article is distributed under the terms of the Creative Commons Attribution 4.0 International License (http://creativecommons.org/licenses/by/4.0/), which permits unrestricted use, distribution, and reproduction in any medium, provided you give appropriate credit to the original author(s) and the source, provide a link to the Creative Commons license, and indicate if changes were made.

\section{REFERENCES}

1. A. Stavrinidis, G. Konstantinidis, K. Vamvoukakis, and K. Zekentes, Mater. Sci. Forum (2017). https://doi.org/10.4028/ www.scientific.net/MSF.897.407.

2. H. Elahipanah, A. Asadollahi, M. Ekström, A. Salemi, C.M. Zetterling, and M. Östling, ECS J. Solid State Sci. Technol. (2017). https://doi.org/10.1149/2.0041705jss.

3. M. Ekström, S. Hou, H. Elahipanah, A. Salemi, M. Östling, and C.M. Zetterling, Mater. Sci. Forum (2018). https://doi. org/10.4028/www.scientific.net/MSF.924.389.

4. S.Y. Jiang, X.Y. Li, and Z.Z. Chen, IEEE Trans Electron Devices (2018). https://doi.org/10.1109/TED.2017.2784098.

5. V.K. Sundaramoorthy, R.A. Minamisawa, L. Kranz, L. Knoll, and G. Alfieri, Mater. Sci. Forum (2018). https://doi. org/10.4028/www.scientific.net/MSF.924.413.

6. N. Kiritani, M. Hoshi, S. Tanimoto, K. Adachi, S.I. Nishizawa, T. Yatsuo, H. Okushi, and K. Arai, Mater. Sci. Forum (2003). https://doi.org/10.4028/www.scientific.net/MSF.433436.669 .

7. K.C. Kragh-Buetow, R.S. Okojie, D. Lukco, and S.E. Mohney, Semicond. Sci. Technol. (2015). https://doi.org/10.1088/ 0268-1242/30/10/105019.

8. H. Shimizu, A. Shima, Y. Shimamoto, and N. Iwamuro, Jpn. J. Appl. Phys. (2017). https://doi.org/10.7567/JJAP.56.04C $\mathrm{R} 15$.

9. D.X. Xu, S.R. Das, C.J. Peters, and L.E. Erickson, Thin Solid Films (1998). https://doi.org/10.1016/S0040-6090(98)0 0547-1.

10. J.P. Gambino, E.G. Colgan, and Mater. Chem. Phys. (1998). https://doi.org/10.1016/S0254-0584(98)80014-X.
11. S.L. Zhang, and M. Östling, Crit. Rev. Solid State Mater. Sci. (2003). https://doi.org/10.1080/10408430390802431.

12. C.K. Lau, Y.C. See, D.B. Scott, J.M. Bridges, S.M. Perna, and R.D. Davies, IEEE International Electron Devices Meeting (IEDM) (1982), pp. 714-717.

13. K. Maex, Mater. Sci. Eng. R (1993). https://doi.org/10.1016/ 0927-796X(93)90001-J.

14. Z. Zhang, S.L. Zhang, M. Östling, and J. Lu, Appl. Phys. Lett. (2006). https://doi.org/10.1063/1.2194313.

15. N. Lundberg, and M. Östling, Solid-State Electron. (1996). h ttps://doi.org/10.1016/0038-1101(96)00071-8.

16. T. Kimoto and J.A. Cooper, Fundamentals of Silicon Carbide Technology (Wiley, Singapore, 2014), p. 33.

17. A.O. Evwaraye, S.R. Smith, and W.C. Mitchel, Appl. Phys. Lett. (1995). https://doi.org/10.1063/1.115233.

18. V.V. Afanas'ev, M. Bassler, G. Pensl, M.J. Schulz, and E. Stein von Kamienski, J. Appl. Phys. (1996). https://doi.org/ 10.1063/1.361254.

19. G. Pasold, F. Albrecht, J. Grillenberger, U. Grossner, C. Hülsen, W. Witthuhn, and R. Sielemann, J. Appl. Phys. (2003). https://doi.org/10.1063/1.1539539.

20. S.K. Lee, C.M. Zetterling, and M. Östling, J. Electron. Mater. (2001). https://doi.org/10.1007/s11664-001-0023-1.

21. N.I. Cho, K.H. Jung, and Y. Choi, Semicond. Sci. Technol. (2004). https://doi.org/10.1088/0268-1242/19/3/003.

22. S.J. Yang, C.K. Kim, I.H. Noh, S.W. Jang, K.H. Jung, and N.I. Cho, Diam. Relat. Mater. (2004). https://doi.org/10.1016/ j.diamond.2003.10.067.

23. K. Smedfors, C.M. Zetterling, and M. Östling, Mater. Sci. Forum (2015). https://doi.org/10.4028/www.scientific.net/M SF.821-823.440.

24. K. Smedfors, Ohmic Contacts for High Temperature Integrated Circuits in Silicon Carbide (KTH Royal Institute of Technology, Stockholm, 2014).

25. A. Ferrario, Processing and characterization of self-aligned $\mathrm{Ni} / \mathrm{Al}$ and $\mathrm{Co}$ ohmic contacts to $4 \mathrm{H}-\mathrm{SiC}$ (KTH Royal Institute of Technology, Stockholm, 2018).

26. T. Fujimura, and S.I. Tanaka, J. Mater. Sci. (1999). https://d oi.org/10.1023/A:1004750016287.

27. C.S. Lim, J.S. Ha, J.H. Ryu, K.H. Auh, I.T. Bae, M. Ishimaru, and Y. Hirotsu, Mater. Trans. (2002). https://doi.org/ 10.2320/matertrans.43.1225.

28. R.S. Okojie, and D. Lukco, J. Appl. Phys. (2016). https://doi. org/10.1063/1.4968572.

29. M. Vivona, G. Greco, C. Bongiorno, S. Di Franco, R. Lo Nigro, S. Scalese, S. Rascunà, M. Saggio, and F. Roccaforte, Mater. Sci. Forum (2018). https://doi.org/10.4028/www.scie ntific.net/MSF.924.377.

30. R. Nipoti, M. Puzzanghera, M. Canino, G. Sozzi, and P. Fedeli, Mater. Sci. Forum (2018). https://doi.org/10.4028/w ww.scientific.net/MSF.924.385.

31. D.K. Schroder, Semiconductor Material and Device Characterization, 3rd edn. (Wiley, New Jersey, 2006), pp. 135157.

32. L. Jablonka, L. Riekehr, Z. Zhang, S.L. Zhang, and T. Kubart, Appl. Phys. Lett. (2018). https://doi.org/10.1063/1.501 1109.

33. R. Pretorius, J.M. Harris, and M.A. Nicolet, Solid-State Electron. (1978). https://doi.org/10.1016/0038-1101(78)9033 5-0.

34. T. Nguyen, H.L. Ho, D.E. Kotecki, and T.D. Nguyen, J. Appl. Phys. (1996). https://doi.org/10.1063/1.362667.

35. M.H. Juang, and H.C. Cheng, Thin Solid Films (1992). h ttps://doi.org/10.1016/0040-6090(92)90703-E.

Publisher's Note Springer Nature remains neutral with regard to jurisdictional claims in published maps and institutional affiliations. 